\title{
Lymphedema: Complications and Management
}

\author{
Pius Agbenorku \\ Reconstructive Plastic Surgery \& Burns Unit, Department of Surgery, Komfo Anokye Teaching Hospital, School \\ of Medical Sciences, College of Health Sciences, Kwame Nkrumah University of Science \& Technology, Kumasi, \\ Ghana \\ Email: pimagben@yahoo.com
}

Received 26 April 2014; revised 23 May 2014; accepted 18 June 2014

Copyright (C) 2014 by author and Scientific Research Publishing Inc. This work is licensed under the Creative Commons Attribution International License (CC BY). http://creativecommons.org/licenses/by/4.0/

(c) (i) Open Access

\begin{abstract}
Introduction: Lymphedema is a condition of the lymphatic system characterized by tissue swelling of body parts especially the limbs as a result of fluid retention. This debilitating condition may result in morbidity and immobility, incapacitating and causing economic burdens as well as affects the individual's physiological and psychological well being. Aim: The aim of the review is to expound extensively on lymphedema and its associated complications and their management. Methods: Information was obtained by searching on-line literatures, published articles and news reports on lymphedema, causes, diagnoses, complications and personal clinical experience. Also patients' data were obtained from Komfo Anokye Teaching Hospital Plastic Surgery Consulting Room and Surgical Operative Records in Kumasi, Ghana. Results: Extensive information was obtained from the various sources which formed the basis of this article highlighting especially the complications which include infections and lymphangiosarcoma resulting from long-standing untreated lymphedema. Conclusion: Since management of the condition is possible, patients are encouraged to seek early treatment when they experience any form of swelling. Long-standing lymphedema may result in serious complications including infections: cellulitis, lymphangitis and lymphangiosarcoma resulting from severe cases of untreated lymphedema.
\end{abstract}

\section{Keywords}

Lymphedema, Lymphatic System, Complications, Lymphangiosarcoma, Psychological, Physiological

\section{Introduction}

Lymphedema is a condition in which there is accumulation of lymph (protein rich fluid) mostly in the lower ex- 
tremities resulting in persistent swelling and oedema; the condition occurs when the lymphatic system is compromised [1]. The condition occurs mostly in girls near menarche and also mostly in women who have undergone breast cancer therapy [2]. Diagnosis is made basically by physical examination and clinical history of the patient [3]. Diagnostic tools include magnetic resonance imaging, isotopic lymphoscintigraphy, direct and indirect lymphography, computed tomography and ultrasonography [4]. Lymphedema may be primary or secondary depending on the cause. Primary lymphedema is mainly caused by congenital malformation of the lymphatic vessels and may either be sporadic or hereditary. Hereditary lymphedema has been categorized into three groups according to age of onset of the condition namely congenital lymphedema occurring age $<1$ year, lymphedema praecox in ages 1 - 35 years and lymphedema tarda in age $>35$ years [5]. Primary lymphedema may occur at any stage but mostly around puberty. Influences of estrogen and inflammation have been considered in some persons as causes of primary lymphedema [2]. An estimated prevalence of 1.15 in 100,000 has been reported in persons below the age of 20 [2]. In children, two main causes that have been identified are Milroy disease and lymphedema distichiasis [6]. Secondary lymphedema is quiet prevalent compared to primary lymphedema. It is also associated with feelings of discomfort, heaviness, functional limitation, disfigurement, psychological distress, and elevated risk of recurrent infection. Secondary causes of lymphedema include contact dermatitis, malignancy, recurrent cellulitis, trauma and filariasis (a parasitic infection occurring mostly in developing countries affecting more than 120 million people in 80 countries around the globe) [4] [7]-[9]. Most common cause of lymphedema is filariasis and occurs mostly in southeast Asia whiles post-surgery lymphedema is quite common in the USA. Blockage of the lymph impairing lymphatic drainage could occur as a result of surgery or radiotherapy especially when axillary irradiation is applied which may cause blockage of lymph vessels [10]-[12]. Axillary approaches involving both surgical and radiotherapy as well as age have been reported as the main risk factor of lymphedema following breast carcinoma treatment [10].

Even though the limbs are mostly involved, other organs of the body could also be affected. Body parts affected may include the limb, head, trunk and around the genitals. Quality of life in patients with lymphedema is mostly affected due to swelling, disfigurement and resulting morbidity implies under productivity and economic burden on family relations and care-takers. Much attention should be given to patients who present with lymphedema to minimize the complications associated with it [13]-[15]. Lymphedema affects these women psychologically, physically and functionally as a result of morbidity [6] [16] [17].

\section{Lymphedema and Lipedema}

Lipedema is condition in which there is accumulation of fat cells in the legs, thigh or buttocks; the hands and feet are however not affected (Figure 1). Lymphedema is characterized by the accumulation of protein rich fluid in the skin tissue and mostly affects the limbs (Figure 2). Pitting occurs when the swollen tissue is pressed in cases of lymphedema where as this does not happen in lipedema. A person with lipedema may eventually develop lymphedema when the fats enter the lymphatic channels, a condition termed as lipo-lymphedema [18].

\section{Complications of Lymphedema}

\subsection{Cellulitis}

Cellulitis is an acute inflammation of the skin, subcutaneous tissue usually complicating wounds and ulcers and characterized with skin colour change, pain, warmth, tenderness and swelling, fever, malaise caused by bacteria, either normal flora or exogenous bacteria as a result of break of the skin caused by cuts, insects bites, blisters, or skin conditions such as chicken pox, eczema, athlete foots may serve as point of entry for bacteria [21] [22]. However, infection can spread to the lymph nodes or bloodstream [23]. Complications from liposuction may predispose persons to bacterial cellulitis; post radical mastectomy, axial lymph node dissection, breast irradiations, overweight may also result in lymphedema cellulitis [24]. The condition could affect any part of the body; however it affects mostly with the lower limbs. It is caused by either Group A streptococcus or staphylococcus aureus in person's with normal host defense [25]. Treatment for cellulitis involves debridement and administration of antibiotics; flucloxacillin or dicloxacillin for mild cellulitis infection involving staphylococcus; a combination of this course with phenoxymethylpenicillin administered orally or intravenously benzylpenicillin or ampicillin/amoxicillin if it involves Streptococcus [21]. Persons at risk include immuno-compromised patients, diabetics and elderly [26]. 


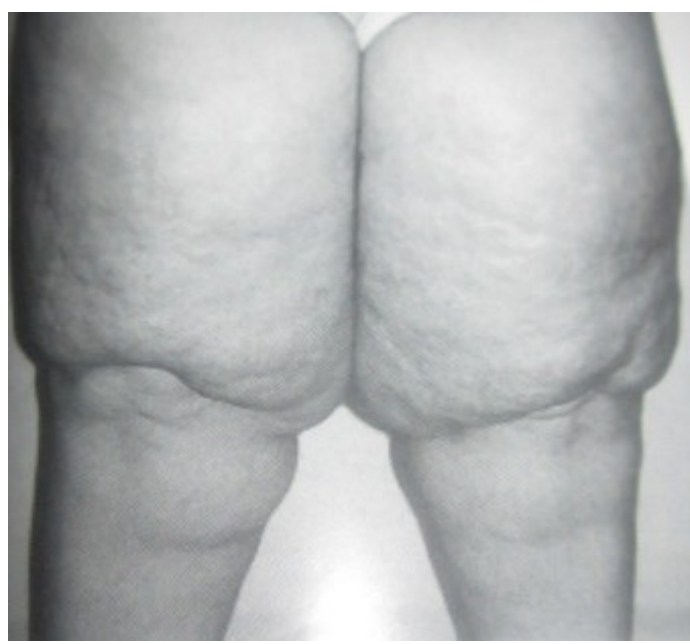

(Source: Ref. [19])

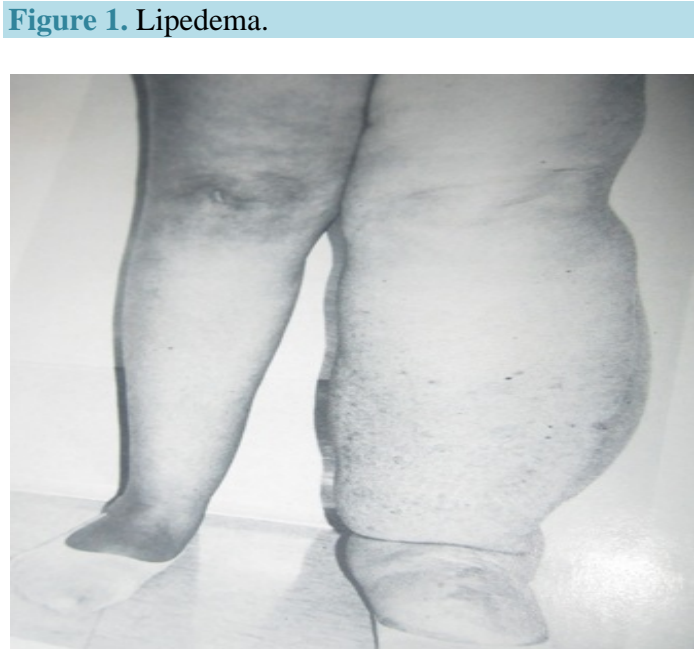

(Source: Ref. [20])

Figure 2. Lymphedema.

\subsection{Lymphangitis}

Lymphangitis is the inflammation of the lymphatic channels/vessels as a result of bacterial infection [27]. These pathogenic organisms are able to enter the lymphatic system when there is a break in the skin resulting from cuts, abrasions, blisters. Lymph vessels which are inflamed are seen as red streaks under the skin extending from the primary site of infection to either the groin or armpit [27] [28]. Persons may experience headache, fever, loss of appetite, malaise, muscle aches, chills and under severe cases the infection may spread from the lymphatic system to the blood vessels causing septicemia which could pose threat to the person's life [27]. Treatment includes antibiotics such as penicillin or clindamycin as well anti-inflammatory drugs and analgesics. However, when the individual does not undergo any anti-microbial therapy, necrosis and ulcerations may occur. Compresses may also be used to help reduce swelling and decrease pain. In cases where abscesses are formed resulting from complications, incision and draining may be required [29]. Lymphangitis is most often caused by streptococcus and less commonly by staphylococcus. In persons with normal host defense, lymphangitis is caused by a species of Group A $\beta$ Haemolytic Streptococcus. Group A $\beta$ Haemolytic Streptococcus, since it progresses rapidly is associated with severe complications such as bacteraemia, sepsis and eventually death [28]. Other organisms such as filarial nematode (Wuchereriabancrofti) also cause lymphatic filariasis. Gram negative rods and bacilli, fungi cause the condition in immuno-compromised patients. Persons at risk of developing the condition are diabetics, immuno-compromised patients, and chronic steroid users amongst others [28]. 


\subsection{Lymphangiosarcoma}

Lymphangiosarcoma is a malignant tumor occurring in patients with long standing primary or secondary lymphedema. This rare condition occurs in both extremities but mostly, the upper extremities [30]. Symptoms seen may include a bruise mark with a purple discoloration or skin nodule on the anterior face which progresses to ulcer with crusting with extensive necrosis of the skin and subcutaneous tissue which metastasizes extensively [31]. This condition was first described by Steward-Treves in 1948 following post mastectomy resulting from lymphedema of the upper extremity; condition now termed as Steward Treves Syndrome with an incidence of 1.6 per 100,000 in the United States, out of which $25 \%$ occurs in the upper extremity [32]. Cardiovascular disease or hypertension has also been reported in relation to lymphangiosarcoma [33]. Lymphangiosarcoma also occurs in persons with congenital or acquired lymphedema [34]. Persons suffering from the lymphedema for 10 years and above have $10 \%$ risk of developing the malignancy. Causes include recurrent infection, radiation as well as extensive fibrosis. As there is no effective therapy early diagnosis of the condition may result in better management. Tumor metastasizing quickly to the lungs and chest wall is a common cause of death in persons with the syndrome; more so, metastasizes to liver and bone is also possible. Persons at risk of suffering from the condition are middle-aged or elderly women with a history of breast cancer and have undergone radical mastectomy [34]. Amputation of the affected limb has been reported to produce a better outcome [31]. Treatment with drugs which show anti-tumour activity such as paclitaxel, doxorubicin, ifosfamide, gemcitabine could be helpful. Bevacizumab has been reported to possibly be effective in the treatment of lymphangiosarcoma [35]-[37].

\section{Materials and Methods}

\subsection{Study Setting}

The Komfo Anokye Teaching Hospital located in Kumasi, the second largest city in Ghana, is a tertiary health facility and referral centre serving persons in the Northern, Upper East and West, Brong Ahafo and Ashanti Regions. Currently the hospital has 1000 bed capacity. The hospital attends to about 679,050 annually consisting in and out patients [38].

\subsection{Management}

Serial bandaging was carried out in all patients who reported during the period under review. There was also excisional debridement for the patients that eventually got ulcerated (cellulitis); they were eventually grafted. Patients were also encouraged to partake in exercises to help them in recuperating as well modify their diet. Medical management of filariasis involves dietary modification, thus, a diet highly rich in protein and medium chain triglycerides as supplement and devoid of fats and administration of anti-filarial drugs such as diethylcarbamizine (DEC), ivermectin and albendazole [39]. Complete Decongestive Therapy (CDT) involves manual lymphatic drainage, multilayer lymphedema bandaging, exercises to activate muscles to aid in lymph drainage and skin care to avoid infection. CDT consists of two phases; Phase I, known as initial reductive phase (which may take up to 6 weeks which involves intensive treatment) and Phase II, a maintenance phase (which involves simple drainage techniques and exercise with wearing compression garments on) [40]. Multilayer lymphedema bandaging involves the use of multiple layers of materials such as inelastic short-stretch bandages to create safe and effective gradient compression to allow the fluid to drain out of the affected limb. Complete Decongestive Therapy has been referred to as the main treatment in persons with lymphedema and is referred to as the gold standard [41] [42] as it provides a better outcome compared to the other treatment modalities available. As the main plan of lymphedema is to reduce swelling and pain, the use of CDT offers more advantage and has been shown to be safe and effective [43]-[46].

\subsection{Data Collection}

Records available for patients with lymphedema and receiving treatment from 2009 to 2013 were retrieved. Patients' data was obtained from Komfo Anokye Teaching Hospital Plastic Surgery Consulting Room and Surgical Operative Records. Data obtained include age, sex, occupation, educational level, marital status, body part affected, cause of the condition. 


\subsection{Data Analysis}

Data obtained was entered into excel and graphs drawn using excel.

\subsection{Ethical Clearance}

Ethical clearance for this study was obtained from the KNUST School of Medical Sciences/KATH Committee on Human Research, Publication and Ethics, Kumasi.

\section{Results}

A total of 27 records were obtained for the study comprising males (33.3\%, $\mathrm{n}=9$ ) and $(66.7 \%, \mathrm{n}=18)$ females (Figure 3) with ages ranging from 12 - 50 years. Thus, ratio of males to females was 1:2. Body parts affected were the upper and lower limbs; $96.3 \%(n=26)$ had their lower limbs while one person had the upper limb affected, 3.7\% ( $\mathrm{n}=1)$ (Figure 4). Congenital lymphedema was found in $1(3.7 \%)$ which was in the youngest person, a female who had the lesion in both her upper limbs; the rest 26 (96.3\%) were secondary (Figure 5).

Complications reported include cellulitis ( $n=5$, Figure 6), lymphangitis ( $=7$, Figure 7), lymphangiosarcoma ( $\mathrm{n}=1$, Figure 8 ) while in the remaining 14 , no complications were recorded.

\section{Discussion}

Severe complications arising from persons with long standing cases of lymphedema is a common occurrence. None of the patients in the current study had developed breast cancer; also there was only a case of lymphangiosarcoma recorded. Lymphedema arising from persons who have undergone breast cancer therapy has been reported; a prevalence ranging from 3\% - 87\% has been recorded in breast cancer survivors. Usually their upper extremity is affected. The severity of the lymphedema correlates with the number of lymph nodes that has been removed as well as the extent of radiation treatment to the axillary region [47].

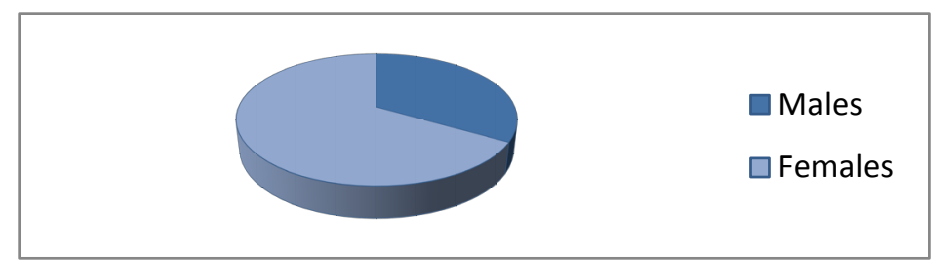

Figure 3. Sex distribution.

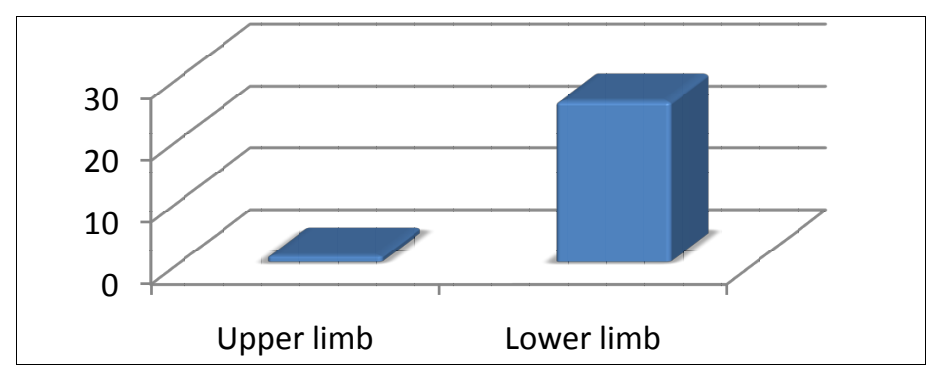

Figure 4. Body parts affected.

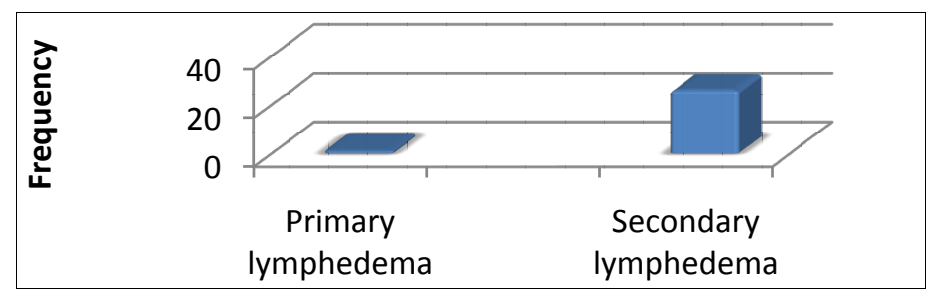

Figure 5. Type of lymphedema. 


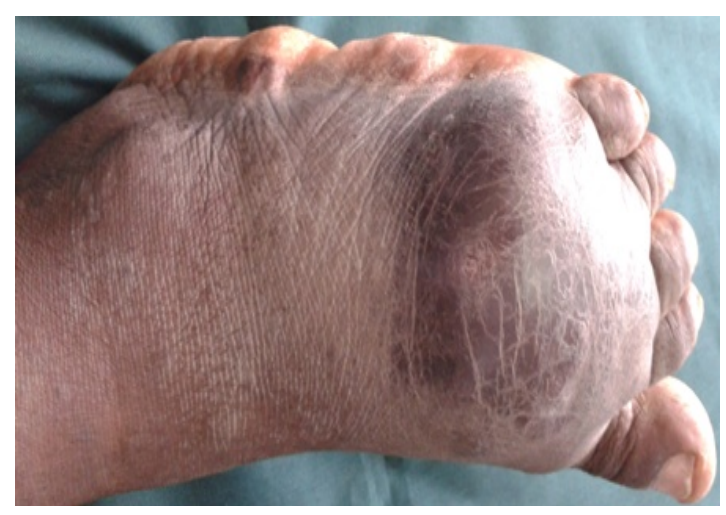

(Source: Author)

Figure 6. Cellulitis following lymphedema.

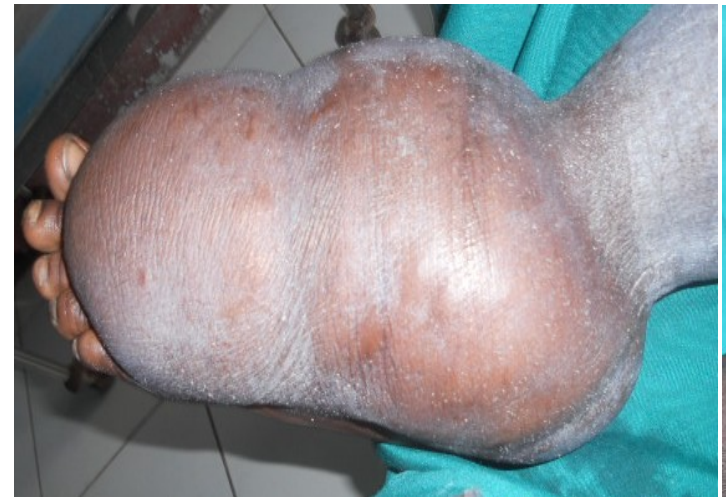

(a) Pre-surgery

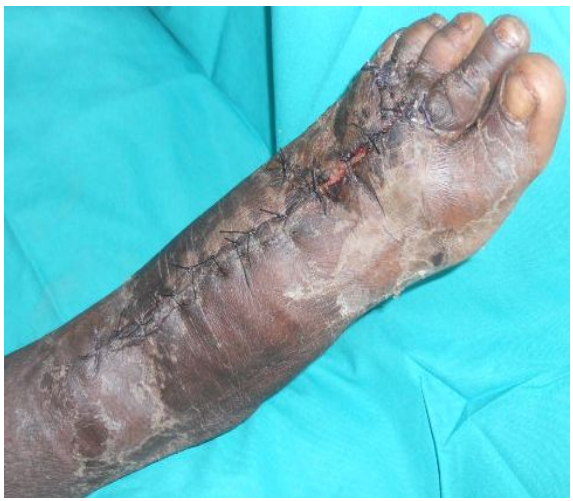

(b) Post-surgery

(Source: Author)

Figure 7. Lymphangitis following lymphedema ((a), (b)).

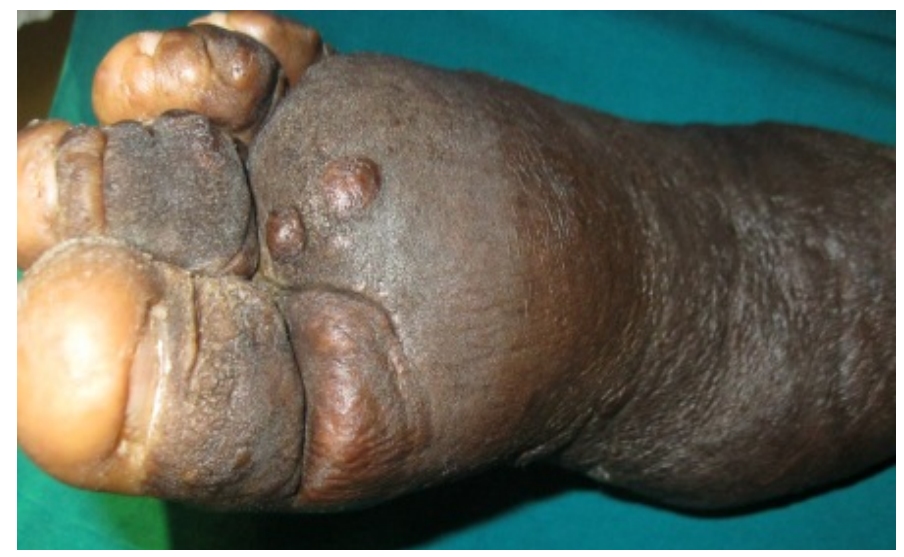

(Source: Author)

Figure 8. Lymphangiosarcoma following long-standing lymphedema.

Lower extremity lymphedema found in persons with prostate cancer has also been reported following extended node dissection with radiation therapy [48]. Seeking medical treatment at early stages would also help conditions to be better managed and complications to be reduced. Since no drug has shown a definite cure for lymphedema, management of the condition is basically to control the progression of swelling as well as avoid development of any related infection.

Females outnumbered males as indicated in the current study. The current study showed increase number of 
females to males; this increase in the number of females may be related to oestrogenic effects as has been reported [2].

Primary lymphedema had a rare occurrence in the study compared to secondary lymphedema. Authors have reported a high occurrence of secondary lymphedema to primary lymphedema. One patient was suffering from filariasis which is mainly responsible for lymphedema across the globe affecting about 120 million people worldwide [49]. Other disease state or trauma may be responsible for the condition in the other patients as seen in persons who have undergone breast cancer therapy [10].

Current study revealed patients had mostly their lower extremities affected. The lower extremities are most often affected compared with the upper extremities. More so, since other areas of the body are rarely affected, none of the patients suffered lymphedema from other areas of their body as pertains to the study.

Psychological and psychosocial issues that burden persons with lymphedema affect their quality of life. The state of morbidity these persons encounter incapacitates them coupled with under productivity and increase in economic burden as family members or care takers would have to invest time taking care of such persons. The inability to move freely as a result of disease conditions has a great toll on the individual as well as pain, discomfort and feeling of heaviness which are associated with the condition.

\section{Conclusion}

With severe morbidities and complications associated with lymphedema, early treatment should be encouraged as the patient may be physiologically and psychologically affected. More so, since complications may result in fatalities, patients should be given adequate care and attention. Early diagnosis is a necessity since a delay may cost the affected person's life. Treatments for persons with lymphedema should span across all aspects of the patient's life to produce a better outcome as the disease condition not only affects the patients but also affects the relatives and caretakers who would have to invest time and resources taking care of the patients causing economic burden and under productivity.

\section{Acknowledgements}

The author sincerely thanks Miss Richcane Amankwa for collecting the data that formed the basis of this study.

\section{Conflict of Interest}

The author declares no conflict of interest in this work.

\section{References}

[1] Lymphedema. http://en.wikipedia.org/wiki/Lymphedema

[2] Smeltzer, D.M., Stickler, G.B. and Schirger, A. (1985) Primary Lymphedema in Children and Adolescents: A FollowUp Study and Review. Pediatrics, 76, 206-218.

[3] Warren, A.G., HåkanBrorson, B.A., Borud, L.J. and Slavin, S.A. (2007) Lymphedema: A Comprehensive Review. Annals of Plastic Surgery, 59, 464-472. http://dx.doi.org/10.1097/01.sap.0000257149.42922.7e

[4] Andrzej, S. and Rockson, S.G. (1998) Lymphedema: Classification, Diagnosis and Therapy. Vascular Medicine, 3, 145-156.

[5] Child, A.H., Beninson, J. and Sarfarazi, M. (1999) Cause of Primary Congenital Lymphedema. Angiology, 50, 325326. http://dx.doi.org/10.1177/000331979905000408

[6] The International Society of Lymphology (2009) The Diagnosis and Treatment of Peripheral Lymphedema. 2009 Consensus Document of the International Society of Lymphology. Lymphology, 11, 51-60.

[7] Hayes, S., Cornish, B. and Newman, B. (2005) Comparison of Methods to Diagnose Lymphedema among Breast Cancer Survivors: 6-Month Follow-Up. Breast Cancer Research and Treatment, 89, 221-226.

[8] Hayes, S., Janda, M., Cornish, B., Battistutta, D. and Newman, B. (2008) Lymphedema Secondary to Breast Cancer: How Choice of Measure Influences Diagnosis, Prevalence, and Identifiable Risk Factors. Lymphology, 41, 18-28.

[9] Ridner, S.H. (2005) Quality of Life and a Symptom Cluster Associated with Breast Cancer Treatment-Related Lymphedema. Support Care Cancer, 13, 904-911.

[10] Bergmann, A., Mattos, I.E., Koiffman, R.J. and Ribeiro, M.J.P. (2008) Upper Limb Lymphedema Following Breast Cancer Surgery: Prevalence and Associated Factors. Lymphology, 40, 96-106. 
[11] Soran, A., Wu, W.C., Dirican, A., Johnson, R., Andacoglu, O. and Wilson, J. (2011) Estimating the Probability of Lymphedema after Breast Cancer Surgery. American Journal of Clinical Oncology, 34, 506-510.

[12] Meeske, K.A., Sullivan-Halley, J., Smith, A.W., McTiernan, A., Baumgartner, K.B., Harlan, L.C., et al. (2009) Risk Factors for Arm Lymphedema Following Breast Cancer Diagnosis in Black Women and White Women. Breast Cancer Research and Treatment, 113, 383-391. http://dx.doi.org/10.1007/s10549-008-9940-5

[13] Foldi, E. and Foldi, M. (1985) Conservative Treatment of Lymphoedema of the Limbs. Angiology, 36, 171-180. http://dx.doi.org/10.1177/000331978503600306

[14] Ko, D.S.C., Lerner, R., Klose, G. and Cosini, A.B. (1998) Effective Treatment of Lymphoedema of the Extremities. Archives of Surgery, 133, 452-458. http://dx.doi.org/10.1001/archsurg.133.4.452

[15] Moffatt, C.J., Franks, P.J., Doherty, D.C., Williams, A.F., Badger, C., Jeffs, E., Bosanquet, N. and Mortimer, P.S. (2003) Lymphoedema: An Underestimated Health Problem. QJM, 96, 731-738. http://dx.doi.org/10.1093/qjmed/hcg126

[16] McWayne, J. and Heiney, S.P. (2005) Psychologic and Social Sequelae of Secondary Lymphedema: A Review. Cancer, 104, 457-466. http://dx.doi.org/10.1002/cncr.21195

[17] Rockson, G. (2010) Lymphatics in the Digestive System: Physiology, Health and Disease. Annals of the New York Academy of Sciences, 1207, E2-E6. http://dx.doi.org/10.1111/j.1749-6632.2010.05804.x

[18] http://www.nhs.uk/conditions/lipoedema/Pages/Introduction.aspx

[19] Miller, T.A. (1979) Lymphedema. In: Grabb, W. and Smith, J., Eds., Plastic Surgery, Little Brown \& Co., Boston, 834.

[20] Mathes, S.J. (2006) Plastic Surgery, Vol. 6: Trunk and Lower Extremity. Saunders, 1462.

[21] Cellulitis. http://en.wikipedia.org/wiki/Cellulitis

[22] Cellulitis. http://emedicine.medscape.com/article/214222-overview

[23] Cellulitis. http://www.mayoclinic.org/diseases-conditions/cellulitis/basics/definition/con-20023471

[24] Lymphedema People. http://www.lymphedemapeople.com/thesite/lymphedema_cellulitis_lymphangit.htm

[25] Cellulitis. http://emedicine.medscape.com/article/214222-overview\#aw2aab6b2b3

[26] Lin, J.N., Chang, L.L., Lai, C.H., Lin, H.H. and Chen, Y.H. (2011) Clinical and Molecular Characteristics of Invasive and Noninvasive Skin and Soft Tissue Infections Caused by Group A Streptococcus. Journal of Clinical Microbiology, 49, 3632-3637. http://dx.doi.org/10.1128/JCM.00531-11

[27] Lymphangitis. http://www.nlm.nih.gov/medlineplus/ency/article/007296.htm

[28] Lymphangitis. http://emedicine.medscape.com/article/966003-overview

[29] Pasternack, M.S. and Swartz, M.N. (2009) Lymphadenitis and Lymphangitis. In: Mandell, G.L., Bennett, J.E. and Dolin, R., Eds., Mandell, Douglas, and Bennett's Principles and Practice of Infectious Diseases, 7th Edition, Elsevier Churchill-Livingstone, Philadelphia.

[30] Hellman, S., DeVita, V.T. and Rosenberg, S. (2001) Cancer: Principles \& Practice of Oncology. Lippincott-Raven, Philadelphia.

[31] Lymphangiosarcoma. http://en.wikipedia.org/wiki/Lymphangiosarcoma

[32] Mack, T.M. (1995) Sarcomas and Other Malignancies of Soft Tissue, Retroperitoneum, Peritoneum, Pleura, Heart, Mediastinum and Spleen. Cancer, 75, 211-244.

[33] Sepah, Y.J., Umer, M., Qureshi, A. and Shaista, K. (2009) Lymphangiosarcoma of the Arm Presenting with Lymphedema in a Woman 16 Years after Mastectomy: A Case Report. Cases Journal, 2, 6887. http://dx.doi.org/10.4076/1757-1626-2-6887

[34] Stewart-Treves Syndrome Clinical Presentation. http://emedicine.medscape.com/article/1102114-clinical\#a0218

[35] Gambini, D., Visintin, R., Locatelli, E., Galassi, B., Bareggi, C., Runza, L., Onida, F. and Tumori, T.M. (2009) Paclitaxel-Dependent Prolonged and Persistent Complete Remission Four Years from First Recurrence of Secondary Breast Angiosarcoma. Medical Oncology Unit, IRCCS Foundation, Ospedale Maggiore Policlinico, Mangiagalli e Regina Elena, Milan, 828-831.

[36] Verdier, E., Carvalho, P., Young, P., Musette, P., Courville, P. and Joly, P. (2007) Lymphangiosarcoma Treated with Liposomal Doxorubicin $\left(\right.$ Caelyx $\left.^{\circledR}\right)$. Annales de Dermatologie et de Vénéréologie, 134, 760-763. http://dx.doi.org/10.1016/S0151-9638(07)92533-8

[37] Sher, T., Hennessy, B.T., Valero, V., Broglio, K., Woodward, W.A., Trent, J., Hunt, K.K., Hortobagyi, G.N. and Gonzalez-Angulo, A.M. (2007) Primary Angiosarcomas of the Breast. Cancer, 110, 173-178. http://dx.doi.org/10.1002/cncr.22784

[38] Komfo Anokye Teaching Hospital. http://www.kathhsp.org/aboutus1.php 
[39] Ansari, M.S. (2005) Medical Treatment of Filariasis and Chyluria. Indian Journal of Urology, 21, 24-26. http://dx.doi.org/10.4103/0970-1591.19546

[40] Treatment for Lymphedema. http://www.nhs.uk/Conditions/Lymphoedema/Pages/Treatment.aspx

[41] Mayrovitz, H.N. (2009) The Standard of Care for Lymphedema: Current Concepts and Physiological Considerations. Lymphatic Research and Biology, 7, 101-108. http://dx.doi.org/10.1089/lrb.2009.0006

[42] Szuba, A., Cooke, J.P., Yousuf, S. and Rockson, S.G. (2000) Decongestive Lymphatic Therapy for Patients with Cancer-Related or Primary Lymphedema. The American Journal of Medicine, 109, 296-300. http://dx.doi.org/10.1016/S0002-9343(00)00503-9

[43] Thomas, R.C., Hawkins, K., Kirkpatrick, S.H., Mondry, T.E., Gabram-Mendola, S. and Johnstone, P.A. (2007) Reduction of Lymphedema Using Complete Decongestive Therapy: Roles of Prior Radiation Therapy and Extent of Axillary Dissection. Journal of the Society for Integrative Oncology, 5, 87-91. http://dx.doi.org/10.2310/7200.2007.004

[44] Koul, R., Dufan, T., Russell, C., Guenther, W., Nugent, Z., Sun, X., et al. (2007) Efficacy of Complete Decongestive Therapy and Manual Lymphatic Drainage on Treatment-Related Lymphedema in Breast Cancer. International Journal of Radiation Oncology, Biology, Physics, 67, 841-846. http://dx.doi.org/10.1016/j.ijrobp.2006.09.024

[45] Godette, K. (2006) Can Manual Treatment of Lymphedema Promote Metastasis? Society for Integrative Oncology, 4, 8-12.

[46] Pinell, X.A., Kirkpatrick, S.H., Hawkins, K., Mondry, T.E. and Johnstone, P.A.S. (2008) Manipulative Therapy of Secondary Lymphedema in the Presence of Loco Regional Tumours. Cancer, 112, 950-954. http://dx.doi.org/10.1002/cncr.23242

[47] Tiwari, P., Coriddi, M., Salani, R. and Povoski S.P. (2013) Breast and Gynecologic Cancer-Related Extremity Lymphedema: A Review of Diagnostic Modalities and Management Options. World Journal of Surgical Oncology, $11,237$. http://dx.doi.org/10.1186/1477-7819-11-237

[48] Rasmusson, E., Gunnlaugsson, A., Blom, R., Björk-Eriksson, T., Nilsson, P., Ahlgen, G., Jönsson, C., Johansson, K. and Kjellén, E. (2013) Low Rate of Lymphedema after Extended Pelvic Lymphadenectomy Followed by Pelvic Irradiation of Node-Positive Prostate Cancer. Radiation Oncology, 8, 271. http://dx.doi.org/10.1186/1748-717X-8-271

[49] de Almeida, A.B. and Freedman, D.O. (1999) Epidemiology and Immunopathology of Bancroftian Filariasis. Microbes and Infection, 1, 1015-1022. http://dx.doi.org/10.1016/S1286-4579(99)80519-X 
Scientific Research Publishing (SCIRP) is one of the largest Open Access journal publishers. It is currently publishing more than 200 open access, online, peer-reviewed journals covering a wide range of academic disciplines. SCIRP serves the worldwide academic communities and contributes to the progress and application of science with its publication.

Other selected journals from SCIRP are listed as below. Submit your manuscript to us via either submit@scirp.org or Online Submission Portal.
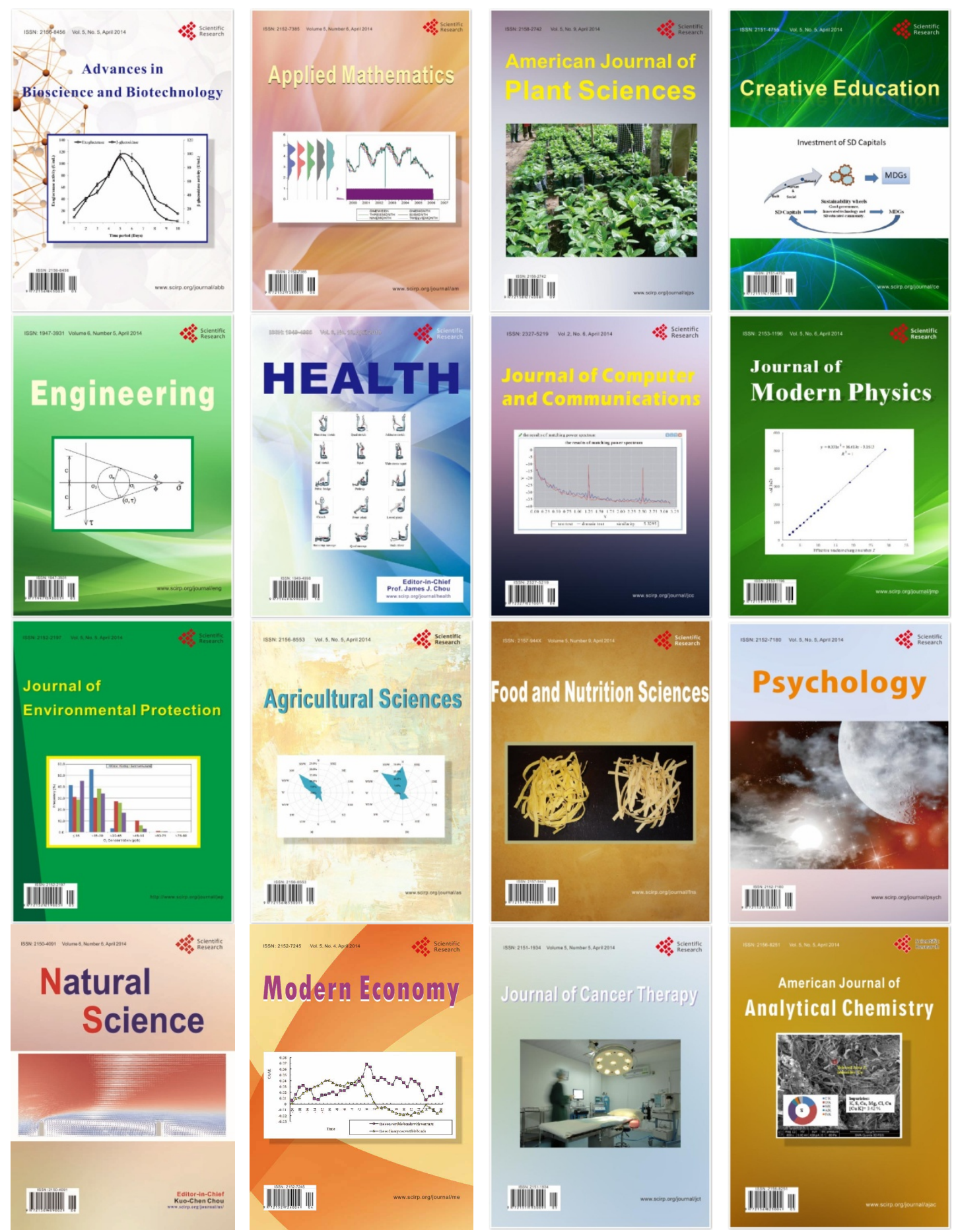